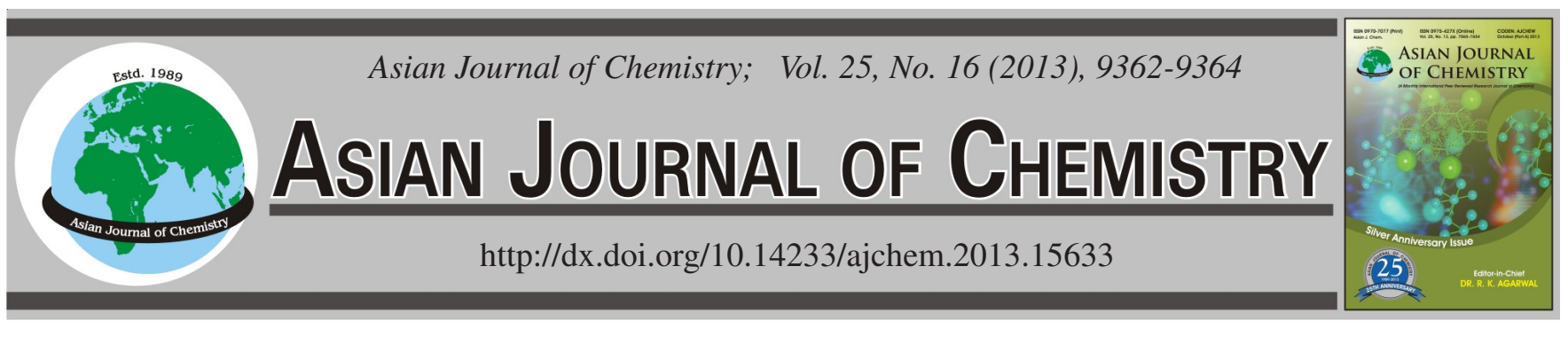

\title{
Synthesis and Characterization of Transition Metal Complexes with 2,2'-[(Propylene-1,3-diyldioxy)bis(nitrilomethylidyne)]diphenol
}

\author{
Feng-Ying Chai ${ }^{1}$, Xin-Ying Zhang ${ }^{2}$, Meng-Meng ZhaO ${ }^{2}$, Zheng-Kun Wang ${ }^{2}$, \\ JiaO-Long MenG ${ }^{2}$, Li-Sha Zhang ${ }^{2}$ and Ke-Tai WANG ${ }^{1, *}$
}

\begin{abstract}
${ }^{1}$ School of Chemical Engineering, Lanzhou University of Arts and Sciences, Lanzhou 730000, P.R. China
${ }^{2}$ School of Chemical and Biological Engineering, Lanzhou Jiaotong University, Lanzhou 730070, P.R. China

*Corresponding author: E-mail: wang_kt@126.com
\end{abstract}

\section{INTRODUCTION}

Transition metal complexes with salen-type or oxime-type ligands are extensively investigated, which have long been used as chelating ligands in the synthesis of transition metal complexes due to their ease of preparation and structural variety. These compounds play a seminal role in the development of modern coordination chemistry, which can accommodate several metal centers and form homo- and heteronuclear metal complexes with favourable properties ${ }^{1}$, such as their enormous variety of structural topologies, as well as their potential applications in optoelectronics, magnetism, non-linear optical materials ${ }^{2}$, biological activity ${ }^{3}$ and catalysis ${ }^{4-8}$. To change the structures or improve the functions of the resulted complexes, herein, a new salamo-type bisoxime ligand, 2,2'-[(propylene1,3-diyldioxy)bis(nitrilomethylidyne)]diphenol $\left(\mathrm{H}_{2} \mathrm{~L}\right)$ and its transition metal complexes have been synthesized and structurally characterized.

\section{EXPERIMENTAL}

2-Hydroxy benzaldehyde ( $\geq 98 \%$ ) and 1,3-dibromo propane was purchased from Alfa Aesar and used without further purification. The other reagents and solvents were analytical grade reagents from Tianjin Chemical Reagent Factory and were used without further purification. Elemental analyses for transition metals were detected by an IRIS ER/ S.WP-1 ICP atomic emission spectrometer. C, $\mathrm{H}$ and $\mathrm{N}$ analyses were carried out with a GmbH VariuoEL V3.00 automatic elemental analyzer. FT-IR spectra were recorded on a VER-
TEX70 FT-IR spectrophotometer, with samples prepared as $\mathrm{KBr}\left(4000-400 \mathrm{~cm}^{-1}\right)$. UV-visible absorption spectra were recorded on a Shimadzu UV-2550 spectrometer. TG-DTA analyses were carried out at a heating rate of $5{ }^{\circ} \mathrm{C} / \mathrm{min}$ on a ZRY-1P thermoanalyzer. Molar conductance value measurements were carried out on a model DDS-11D type conductivity bridge using $1.0 \times 10^{-3} \mathrm{~mol} \mathrm{dm}^{-3}$ solution in DMF at $21^{\circ} \mathrm{C}$. Melting points were obtained by use of an X4 microscopic melting point apparatus made in Beijing Taike Instrument Limited Company and were uncorrected.

Synthesis of 2,2' -[(propylene-1,3-diyldioxy)bis(nitrilomethylidyne)]diphenol $\left(\mathbf{H}_{2} \mathbf{L}\right)$ : The ligand $\mathrm{H}_{2} \mathrm{~L}$ was synthesized with a slightly modified method reported literature ${ }^{1}$. Synthetic route to salamo-type bisoxime ligand $\mathrm{H}_{2} \mathrm{~L}$ is shown in Fig. 1.<smiles>O=C1c2ccccc2C(=O)N1O</smiles>

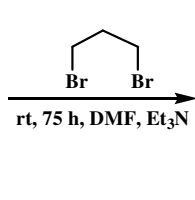<smiles>O=C1NC(=O)c2ccccc21</smiles><smiles>CCON1C(=O)c2ccccc2C1=O</smiles>

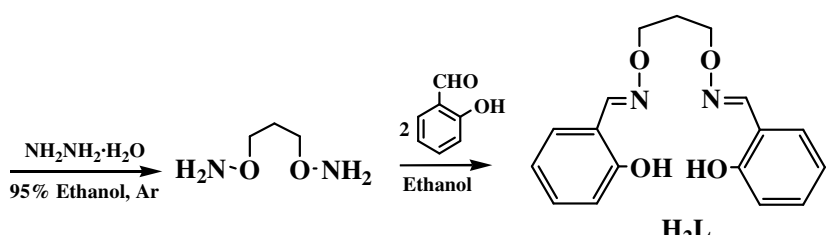

$\mathrm{H}_{2} \mathrm{~L}$

Fig. 1. Synthetic route to the salamo-type bisoxime compound 
1,3-Bis(phthalimidooxy)propane was synthesized according to an analogous method reported earlier ${ }^{1}$.

1,3-Bis(aminooxy)propane was synthesized according to an analogous method reported earlier ${ }^{1} .{ }^{1} \mathrm{H} \mathrm{NMR}(400 \mathrm{MHz}$, $\left.\mathrm{CDCl}_{3}\right) \delta: 1.88(\mathrm{~m}, 2 \mathrm{H}), 3.77(\mathrm{t}, 4 \mathrm{H}), 5.00(\mathrm{~s}, 4 \mathrm{H})$.

Synthesis of $\mathbf{H}_{2} \mathbf{L}$ : To an ethanolic solution $(10 \mathrm{~mL})$ of 2-hydroxy benzaldehyde (366.4 $\mathrm{mg}, 3 \mathrm{mmol}$ ) was added an ethanolic solution (5 mL) of 1,3-bis(aminooxy)propane (159.2 $\mathrm{mg}, 1.5 \mathrm{mmol})$. The solution had been stirred at $55^{\circ} \mathrm{C}$ for $4 \mathrm{~h}$. When the solution cooled to room temperature, the resulting solid was filtered and washed with ethanol and ethanol/hexane (1:4), respectively. The product was dried under reduced pressure and purified with recrystallization from ethanol to obtain $385.7 \mathrm{mg}$ of white crystalline solid $\mathrm{H}_{2} \mathrm{~L}$. Yield, $81.8 \%$. m.p. 80-81 ${ }^{\circ} \mathrm{C} .{ }^{1} \mathrm{H}$ NMR (400 MHz, $\left.\mathrm{CDCl}_{3}\right) \delta: 2.09$ (t, $J=6.0$ $\mathrm{Hz}, 2 \mathrm{H}), 4.25$ (t, $J=6.0 \mathrm{~Hz}, 4 \mathrm{H}), 6.88(\mathrm{t}, J=8.0 \mathrm{~Hz}, 4 \mathrm{H}), 7.11$ (s, 2H), 7.18 (s, 2H), $8.13(\mathrm{~s}, 2 \mathrm{H}), 9.76(\mathrm{~s}, 2 \mathrm{H})$.

Synthesis of $\mathbf{C u}($ II) complex: A solution of copper(II) acetate monohydrate $(20 \mathrm{mg}, 0.10 \mathrm{mmol})$ in ethanol $(5 \mathrm{~mL})$ was added dropwise to a solution of $\mathrm{H}_{2} \mathrm{~L}(31.4 \mathrm{mg}, 0.10 \mathrm{mmol})$ in ethanol $(3 \mathrm{~mL})$ at room temperature. The solution became green immediately and formed the brown flocculent precipitate, then stirred for $3.5 \mathrm{~h}$ at room temperature. The resulting solid was filtered off, washed with ethanol/ether (1:4) and ether, respectively. The product was dried in vacuo and obtained $31.8 \mathrm{mg}$ of $\mathrm{Cu}(\mathrm{II})$ complex (Yield $79.7 \%$ ).

Synthesis of Ni(II) complex: To an ethanolic solution ( $3 \mathrm{~mL}$ ) of $\mathrm{H}_{2} \mathrm{~L}$ ( $\left.31.4 \mathrm{mg}, 0.10 \mathrm{mmol}\right)$ was added an ethanolic solution $(6 \mathrm{~mL})$ of nickel(II) acetate tetrahydrate $(24.8 \mathrm{mg}$, $0.10 \mathrm{mmol})$. After the mixture solution had been stirred at $55^{\circ} \mathrm{C}$ for $4 \mathrm{~h}$. The formed precipitate was separated by filtration and washed successively with ethanol and ether. The product was dried under reduced pressure to obtain $27.9 \mathrm{mg}$ of $\mathrm{Ni}$ (II) complex (Yield $66.9 \%$ ).

Synthesis of Co(II) complex: To an ethanolic solution ( $2 \mathrm{~mL}$ ) of $\mathrm{H}_{2} \mathrm{~L}$ ( $31.4 \mathrm{mg}, 0.10 \mathrm{mmol}$ ) was added an ethanolic solution $(8 \mathrm{~mL})$ of cobalt(II) acetate tetrahydrate $(24.9 \mathrm{mg}$, $0.10 \mathrm{mmol})$. After the mixture solution had been stirred at $55^{\circ} \mathrm{C}$ for $3 \mathrm{~h}$. The resulting solid was filtered off, washed with ethanol and ether, respectively. The product was dried in vacuo and obtained $27.8 \mathrm{mg}$ of Co(II) complex (Yield $66.6 \%$ ).
Synthesis of Mn(II) complex: To an ethanolic solution ( $2 \mathrm{~mL}$ ) of $\mathrm{H}_{2} \mathrm{~L}$ ( $31.4 \mathrm{mg}, 0.10 \mathrm{mmol}$ ) was added an ethanolic solution $(6 \mathrm{~mL})$ of manganese(II) acetate tetrahydrate $(24.5$ $\mathrm{mg}, 0.10 \mathrm{mmol})$. After the mixture solution had been stirred at $55^{\circ} \mathrm{C}$ for $6 \mathrm{~h}$, the formed precipitate was separated by filtration and washed with ethanol and ether, respectively. The product was dried under reduced pressure to obtain $26.0 \mathrm{mg}$ of $\mathrm{Mn}$ (II) complex (Yield $63.0 \%$ ).

\section{RESULTS AND DISCUSSION}

A new salamo-type bisoxime ligand $\mathrm{H}_{2} \mathrm{~L}$ and a series of complexes have been synthesized. The composition were confirmed by elemental analyses and characterized by IR, UVvisible spectra, molar conductances and TG-DTA analyses.

Composition of $\mathrm{H}_{2} \mathrm{~L}$ and metal complexes: The colour, yields and elemental analytical results of the synthesized salamo-type bisoxime ligand and its transition metal complexes are presented in Table-1.

Their compositions agree with the formulae. The ligand is stable in air and soluble in methanol, ethanol, acetone, chloroform, dichloromethane, tetrahydrofuran, acetonitrile, ether, DMF and DMSO while insoluble in $n$-hexane. The molar conductance values of the complexes at $21^{\circ} \mathrm{C}$ in $1.0 \times 10^{-3}$ mol dm${ }^{-3}$ DMF solutions are 1.67, 1.58, 1.60 and $1.72 \mathrm{~S} \mathrm{~cm}^{2}$ $\mathrm{mol}^{-1}$, respectively, indicating that all of these complexes are non-electrolytes ${ }^{9}$.

IR spectra of $\mathrm{H}_{2} \mathrm{~L}$ and complexes: The IR spectral details of the salamo-type bisoxime ligand $\mathrm{H}_{2} \mathrm{~L}$ and its corresponding transition metal complexes are given in Table-2.

The characteristic $\mathrm{C}=\mathrm{N}$ stretching band of the free ligand $\mathrm{H}_{2} \mathrm{~L}$ appears at $1609 \mathrm{~cm}^{-1}$, while the $\mathrm{C}=\mathrm{N}$ bands of the complexes are observed at 1604, 1605, 1603 and $1603 \mathrm{~cm}^{-1}$, respectively. The Ar-O stretching band occurs at $1270 \mathrm{~cm}^{-1}$ for $\mathrm{H}_{2} \mathrm{~L}$, whereas those at $1246,1247,1242$ and $1240 \mathrm{~cm}^{-1}$ for the complexes, respectively. These shifts of $\mathrm{C}=\mathrm{N}$ and $\mathrm{Ar}-\mathrm{O}$ stretching frequencies indicate that the $\mathrm{M}-\mathrm{N}$ and $\mathrm{M}-\mathrm{O}$ bonds are formed between the transition metal ions and the oxime $\mathrm{N}$ and the phenolic $\mathrm{O}$ atoms of deprotonated $(\mathrm{L})^{2-}$ unit $^{1 \mathrm{a}}$. Meanwhile, a O-H stretching band of the free ligand $\mathrm{H}_{2} \mathrm{~L}$ at 3410 $\mathrm{cm}^{-1}$ disappears in the complexes, indicating the oxygen in phenolic alcohol of the complexes has been deprotonated and

TABLE-1

COLOUR, YIELDS AND ANALYTICAL DATA OF $\mathrm{H}_{2}$ LAND ITS TRANSITION METAL COMPLEXES

\begin{tabular}{llllllll}
\hline \multicolumn{2}{c}{ Compound } & \multirow{2}{*}{ m.f. (m.w.) } & \multirow{2}{*}{ Colour } & \multirow{2}{*}{\begin{tabular}{c} 
Yield \\
\cline { 6 - 8 } \cline { 6 - 8 }
\end{tabular}} & & & \multicolumn{4}{c}{ Found (calcd.) (\%) } \\
\hline $\mathrm{H}_{2} \mathrm{~L}$ & $\mathrm{C}_{17} \mathrm{H}_{18} \mathrm{~N}_{2} \mathrm{O}_{4}(314.3)$ & White & 81.8 & $64.88(64.96)$ & $5.80(5.77)$ & $8.65(8.91)$ & $\mathrm{M}$ \\
{$[\mathrm{CuL}] \cdot 0.5 \mathrm{CH}_{3} \mathrm{CH}_{2} \mathrm{OH}$} & $\mathrm{C}_{18} \mathrm{H}_{19} \mathrm{~N}_{2} \mathrm{O}_{4.5} \mathrm{Cu}(398.9)$ & Gray & 79.7 & $53.97(54.20)$ & $5.02(4.80)$ & $6.94(7.02)$ & $15.96(15.93)$ \\
{$[\mathrm{NiL}] \cdot \mathrm{CH}_{3} \mathrm{CH}_{2} \mathrm{OH}$} & $\mathrm{C}_{19} \mathrm{H}_{22} \mathrm{~N}_{2} \mathrm{O}_{5} \mathrm{Ni}(417.1)$ & Green & 66.9 & $54.88(54.71)$ & $5.11(5.32)$ & $6.58(6.72)$ & $14.32(14.07)$ \\
{$[\mathrm{CoL}] \cdot \mathrm{CH}_{3} \mathrm{CH}_{2} \mathrm{OH}$} & $\mathrm{C}_{19} \mathrm{H}_{22} \mathrm{~N}_{2} \mathrm{O}_{5} \mathrm{Co}(417.3)$ & Yellow & 66.6 & $54.74(54.68)$ & $5.19(5.31)$ & $6.53(6.71)$ & $14.35(14.12)$ \\
{$[\mathrm{MnL}] \cdot \mathrm{CH}_{3} \mathrm{CH}_{2} \mathrm{OH}$} & $\mathrm{C}_{19} \mathrm{H}_{22} \mathrm{~N}_{2} \mathrm{O}_{5} \mathrm{Mn}(413.3)$ & White & 63.0 & $55.42(55.21)$ & $5.22(5.36)$ & $6.64(6.78)$ & $13.43(13.29)$ \\
\hline
\end{tabular}

TABLE-2

IR SPECTRAL $\left(\mathrm{cm}^{-1}\right)$ DATA FOR $\mathrm{H}_{2}$ L AND ITS TRANSITION METAL COMPLEXES

\begin{tabular}{lcccc}
\hline \multicolumn{1}{c}{ Compound } & $v(\mathrm{C}=\mathrm{N})$ & $v(\mathrm{Ar}-\mathrm{O})$ & $v(\mathrm{O}-\mathrm{H})$ & $v(\mathrm{C}=\mathrm{C})$ benzene ring skeleton \\
\hline $\mathrm{H}_{2} \mathrm{~L}$ & 1609 & 1270 & 3410 & $1572,1494,1472$ \\
{$[\mathrm{CuL}] \cdot 0.5 \mathrm{CH}_{3} \mathrm{CH}_{2} \mathrm{OH}$} & 1604 & 1246 & 3439 & $1536,1470,1445$ \\
{$[\mathrm{NiL}] \cdot \mathrm{CH}_{3} \mathrm{CH}_{2} \mathrm{OH}$} & 1605 & 1247 & 3429 & $1538,1476,1443$ \\
{$[\mathrm{CoL}] \cdot \mathrm{CH}_{3} \mathrm{CH}_{2} \mathrm{OH}$} & 1603 & 1242 & 3429 & $1543,1470,1441$ \\
{$[\mathrm{MnL}] \cdot \mathrm{CH}_{3} \mathrm{CH}_{2} \mathrm{OH}$} & 1603 & 1240 & 3421 & $1545,1471,1440$ \\
\hline
\end{tabular}


TABLE-3

UV-VISIBLE SPECTRA DATA OF $\mathrm{H}_{2}$ L AND ITS TRANSITION METAL COMPLEXES

\begin{tabular}{lccc|cc}
\hline \multirow{2}{*}{ Compound } & \multirow{2}{*}{$\mathrm{C}\left(\times 10^{-4} \mathrm{~mol} \mathrm{~L}^{-1}\right)$} & \multicolumn{2}{c}{ First band } & \multicolumn{2}{c}{ Second band } \\
\cline { 3 - 6 } & & $\lambda_{\max }(\mathrm{nm})$ & $\varepsilon_{1}\left(\times 10^{4} \mathrm{~L} \mathrm{~mol}^{-1} \mathrm{~cm}^{-1}\right)$ & $\lambda_{\max 2}(\mathrm{~nm})$ & $\varepsilon_{2}\left(\times 10^{4} \mathrm{~L} \mathrm{~mol}^{-1} \mathrm{~cm}^{-1}\right)$ \\
\hline $\mathrm{H}_{2} \mathrm{~L}$ & 1.00 & 267 & 2.29 & 313 & 1.19 \\
{$[\mathrm{CuL}] \cdot 0.5 \mathrm{CH}_{3} \mathrm{CH}_{2} \mathrm{OH}$} & 1.00 & 269 & 1.04 & 300 & 0.59 \\
{$[\mathrm{NiL}] \cdot \mathrm{CH}_{3} \mathrm{CH}_{2} \mathrm{OH}$} & 1.00 & 280 & 1.12 & 289 & 0.40 \\
{$[\mathrm{CoL}] \cdot \mathrm{CH}_{3} \mathrm{CH}_{2} \mathrm{OH}$} & 1.00 & 279 & 0.89 & 292 & 0.68 \\
{$[\mathrm{MnL}] \cdot \mathrm{CH}_{3} \mathrm{CH}_{2} \mathrm{OH}$} & 1.00 & 275 & 1.09 & 288 & 0.70 \\
\hline
\end{tabular}

coordinated to the metals. In the $1572-1440 \mathrm{~cm}^{-1}$ region, the observed bands were attributed to aromatic $\mathrm{C}=\mathrm{C}$ vibrations. In addition, infrared spectra of the complexes show the expected strong absorption bands due to $\mathrm{v}(\mathrm{O}-\mathrm{H})$ at 3439-3421 $\mathrm{cm}^{-1}$, which are the evidence for the existence of ethanol molecules ${ }^{1 \mathrm{e}}$.

UV-visible spectra of $H_{2} L$ and complexes: The UVvisible spectra of $\mathrm{H}_{2} \mathrm{~L}$ and its corresponding complexes in diluted DMF solution are presented in Table-3. The spectra of the complexes are similar to each other, but are different from the spectrum of the ligand $\mathrm{H}_{2} \mathrm{~L}$. The UV-visible spectrum of the free ligand $\mathrm{H}_{2} \mathrm{~L}$ exhibits two absorption peaks at 267 and $313 \mathrm{~nm}$. The former absorption peak at $267 \mathrm{~nm}$ can be assigned to the $\pi-\pi^{*}$ transition of the benzene rings, while the latter one at $313 \mathrm{~nm}$ can be attributed to the intra-ligand $\pi-\pi^{*}$ transition of the $\mathrm{C}=\mathrm{N}$ bonds ${ }^{10}$.

Compared with the absorption peak of the free ligand, the former absorption peaks at 269, 280, 279 and $275 \mathrm{~nm}$ are observed in $\mathrm{Cu}(\mathrm{II}), \mathrm{Ni}(\mathrm{II}), \mathrm{Co}(\mathrm{II})$ and $\mathrm{Mn}(\mathrm{II})$ complexes, respectively, which are bathochromically shifted by $2-13 \mathrm{~nm}$. Meanwhile, the second absorption peaks at 300, 289, 292 and $288 \mathrm{~nm}$ are observed in $\mathrm{Cu}(\mathrm{II}), \mathrm{Ni}$ (II), $\mathrm{Co}(\mathrm{II})$ and $\mathrm{Mn}$ (II) complexes, respectively, which are hypsochromically shifted by $13-25 \mathrm{~nm}$. These indicate that the oxime nitrogen atom is involved in coordination to the metal atom ${ }^{11,12}$. In addition, the new band observed at $362 \mathrm{~nm}$ for the $\mathrm{Cu}$ (II) complex is assigned to the $n-\pi *$ charge transfer transition from the filled p $\pi$ orbital of the bridging phenolic oxygen to the vacant $d$ orbital of the $\mathrm{Cu}(\mathrm{II})$ ion, which is characteristic of the transition metal complexes with $\mathrm{N}_{2} \mathrm{O}_{2}$ coordination spheres ${ }^{13}$.

Thermal properties: The thermal decomposition processes of the complexes compared with the ligand are significantly different. The ligand has a sharp endothermic peak at $83{ }^{\circ} \mathrm{C}$ in the DTA curve, with no weight loss in the TG curve and has a exothermic peak at $266{ }^{\circ} \mathrm{C}$, weight loss occurs at $239^{\circ} \mathrm{C}$ in the corresponding TG curve. The ligand decomposed completely by one step. However, the DTA curves of all the complexes have endothermic peaks in the range $78-142{ }^{\circ} \mathrm{C}$, with weight loss in the TG curve. The weight loss values of $\mathrm{Cu}(\mathrm{II}), \mathrm{Ni}(\mathrm{II}), \mathrm{Co}(\mathrm{II})$ and $\mathrm{Mn}$ (II) complexes are 5.6, 11.5, 10.7 and $11.8 \%$, respectively, which are close to the theoretical values $(5.8,11.1,11.0$ and $11.2 \%)$ of losing corresponding ethanol molecule. The complexes have no sharp melting point. All of the complexes have two exothermic peaks at $300{ }^{\circ} \mathrm{C}$, with apparent weight loss, which are staged oxidative decomposition of the complexes. On further heating, the final solid products are likely to $\mathrm{CuO}, \mathrm{NiO}, \mathrm{CoO}$ and $\mathrm{Mn}_{2} \mathrm{O}_{3}$ with a residual value of 19.3, 17.2, 17.0 and $18.5 \%$, which was found to be close to the calculated values $(19.9,17.9,17.9$ and $19.1 \%)$ when the temperature is above $800^{\circ} \mathrm{C}$.

\section{REFERENCES}

1. (a) W.K. Dong, Y.X. Sun, C.Y. Zhao, X.Y. Dong and L. Xu, Polyhedron, 29, 2087 (2010); (b) W.K. Dong, Y.X. Sun, G.H. Liu, L. Li, X.Y. Dong and X.H. Gao, Z. Anorg. Allg. Chem., 638, 1370 (2012); (c) W.K. Dong, X.N. He, H.B. Yan, Z.W. Lv, X. Chen, C.Y. Zhao and X.L. Tang, Polyhedron, 28, 1419 (2009); (d) W.K. Dong, Y.X. Sun, Y.P. Zhang, L. Li, X.N. He and X.L. Tang, Inorg. Chim. Acta, 362, 117 (2009); (e) W.K. Dong, L. Li, C.F. Li, L. Xu and J.G. Duan. Spectrochim. Acta A, 71, 650 (2008); (f) W.K. Dong, J.Y. Shi, L. Xu, J.K. Zhong, J.G. Duan and Y.P. Zhang, Appl. Organometal. Chem., 22, 89 (2008).

2. P.G. Lacroix, Eur. J. Inorg. Chem., 339 (2001).

3. S.S. Sun, C.L. Stern, S.T. Nguyen and J.T. Hupp, J. Am. Chem. Soc., 126, 6314 (2004).

4. D. Ülkü, F. Ercan, O. Atakol and F.N. Dinçer, Acta Crystallogr., C53, 1056 (1997).

5. J. Kim, B. Chen, T.M. Reineke, H. Li, M. Eddaoudi, D.B. Moler, M. O'Keeffe and O.-M. Yaghi, J. Am. Chem. Soc., 123, 8239 (2001).

6. S. Durmus, B.M. Ates, O. Atakol and F. Ercan, Z. Kristallogr., 220, 973 (2005).

7. J. Reglinski, S. Morris and D.E. Stevenson, Polyhedron, 21, 2167 (2002).

8. K. Ueno and A.E. Martel, J. Phys. Chem., 60, 1270 (1956).

9. W.J. Geary, Coord. Chem. Rev., 1, 81 (1971).

10. T. Ghosh, B. Mondal, T. Ghosh, M. Sutradhar, G. Mukherjee and M.G.B. Drew, Inorg. Chim. Acta, 360, 1753 (2007).

11. H.E. Smith, Chem. Rev., 83, 359 (1983).

12. S. Akine, T. Taniguchi and T. Nabeshima, Chem. Lett., 30, 682 (2001).

13. L. Gomes, E. Pereira and B. Castro, J. Chem. Soc. Dalton Trans., 1373 (2000). 